\title{
Association between physical activity patterns and anthropometric characteristics of adults: an issue of public health?
}

\author{
Filipe Manuel Clemente ${ }^{1,2}$, Fernando Manuel Lourenço Martins ${ }^{2,3}$, Pantelis Theodoros Nikolaidis ${ }^{4}$, \\ Rui Sousa Mendes ${ }^{3}$
}

${ }^{1}$ Instituto Politécnico de Viana do Castelo, Escola Superior de Desporto e Lazer, Portugal; ${ }^{2}$ Instituto de Telecomunicações, Delegação da Covilhã, Portugal; ${ }^{3}$ Polytechnic Institute of Coimbra, Coimbra College of Education, RoboCorp, ASSERT, Portugal; ${ }^{4}$ Department of Physical and Cultural Education, Hellenic Army Academy, Athens, Greece

\section{Summary}

Study aim: The aim of this study was to evaluate the association between objectively measured daily physical activity (PA) and body fat mass (BF) and body mass index (BMI). A further aim was to analyse the variance of PA between quartiles of BF and BMI.

Material and methods: A cross-sectional, observational study of 126 university students (53 males aged 20.46 \pm 2.04 years and 73 female aged $19.69 \pm 1.32$ years) was conducted.

Results: The female participants and PA characteristics explain $57.10 \%$ of BF variance and the model was statistically significant $\left(F_{(6,875)}=196.38 ; p=0.001\right)$. BMI was also included in the model. Standard binary logistic regression was used to test the hypothesis that female sex and PA characteristics can influence overweight. The full model containing all variables was statistically significant $\left(G^{2}(6)=58.598\right.$, p-value $\left.=0.001\right)$. Analysis of variance between BF quartiles revealed statistically significant differences in male participants in light PA $(p=0.001 ; \mathrm{ES}=0.09)$, moderate PA $(p=0.001 ; \mathrm{ES}=0.042)$ and vigorous $\mathrm{PA}(p=0.001 ; \mathrm{ES}=0.130)$.

Conclusions: The statistical model in the regression analysis suggests that low and vigorous levels of PA explain 57\% of BF variance in female participants.

Keywords: Physical activity - Accelerometry - Body fat mass - Body mass index - Young adults

\section{Introduction}

Emerging adulthood, i.e. the period of age ranging from 18 to 25 years, has been identified as a crucial transitional period, since it lies between adolescence and adulthood, and as a correlate of overweight and obesity during adulthood [15]. This period is characterized by deterioration in health-related habits, e.g. poorer eating habits and decrease of physical activity (PA) [17]. In addition, standard intervention programmes do not meet the weight control needs in this population [10]. Psychological markers in emerging adulthood were associated with less PA and a higher body mass index in adulthood [2]. Emerging adulthood also shows relatively low life satisfaction [18], whereas PA has been suggested as a mean of depression intervention in this period [5].

University students undergo physiological and psychological changes affecting their PA levels and nutrition habits, which in turn result in considerable gains in body mass $[8,13]$. Also, prevalence of overweight and plasma lipid levels were found to be above normal in university students [11]. Although the abovementioned studies enhanced our understanding of the relationship between PA and markers of overweight and obesity, there is a lack of information about objectively measured PA and domains of PA, such as sedentary, light, moderate and vigorous during emerging adulthood. Instead of using objective assessment methods (e.g. accelerometer), previous studies have relied mostly on subjective methods (e.g. questionnaire) $[7,21]$. In addition, sedentary, light, moderate and vigorous PA might be associated differently with $\mathrm{BMI}$ and BF [23]. Such information would be valuable for both researchers and health professionals involved in the management of overweight and obesity. The aim of the present study was to investigate the relationship between objectively measured PA and markers of overweight and obesity in young female and male adults. 


\section{Materials and methods}

\section{Participants}

One hundred and twenty-six university students (53 males aged $20.46 \pm 2.04$ years and 73 females aged $19.69 \pm 1.32$ years) participated in this study. From these undergraduate students, $26.19 \%$ were amateur athletes (males: $\mathrm{n}=20$; females: $\mathrm{n}=13$ ). Most of them lived in rented flats $(63 \%)$ or in the campus hostels $(19 \%)$ close to the campus, so they were not far away from the lecture halls. The Research Ethics Committee of the Polytechnic Institute of Coimbra approved this study (code: 01.09/2015). All volunteers signed informed consent forms prior to their participation in the study. The study followed the ethical standards of the Declaration of Helsinki for research on humans.

\section{Procedures}

Participants were assessed individually at a single session before wearing the accelerometer. Upon arriving at the laboratory for the session, participants completed several paper and pencil self-report measures asking about their PA and mental and physical health.

The anthropometric measurements were made at the university by trained researchers to minimize the interobserver variability. Body mass and height were measured following standardized recommendations with an electronic scale $($ Tanita SC $330 \mathrm{~S}$; precision $=100 \mathrm{~g}$, range $=$ 0-270 kg) and a stadiometer (model 213, SAGE, precision $0.1 \mathrm{~cm}$, range $=0-230 \mathrm{~cm}$ ), respectively. The average of two measurements was taken. Body mass index (BMI) was calculated as body mass (in $\mathrm{kg}$ ) divided by height ${ }^{2}$ (in meters). The $\mathrm{BF}(\mathrm{kg})$ and $\%$ of $\mathrm{BF}$ were also collected from the Tanita's measurement.

Immediately after completing the physical fitness testing, participants were fitted with an ActiGraph wGT3XBT activity monitor (Shalimar, FL, USA) that they wore for the next 7 days. The wGT3X-BT is a tri-axial, solidstate accelerometer designed to measure body acceleration in the three planes. Participants were instructed to wear the accelerometers over the right iliac crest under their clothes for 24 hours including during sleep and to remove it only for showers and water-based activities such as swimming. At the end of the 7-day monitoring period participants turned in their accelerometers, and the accelerometer data were analysed using ActiLife 6.0 software.

The accelerometers were initialized and downloaded using the ActiLife software provided by the manufacturer. The data were collected in 10-s epochs. To analyse the data, the 10-s epochs were collapsed into 60-s epochs, which is a validated epoch for young adults. Non-wear time was counted as 60 consecutive minutes with zero counts, with the allowance for $1 \mathrm{~min}$ with counts greater than zero.
Non-wear was excluded from further analysis. Accelerometer data were processed (ActiLife 6.0.) to provide values for total daily and hourly counts per minute (cpm) sedentary time (minutes and \%), light PA (minutes and $\%$ ), moderate PA (minutes and \%), vigorous PA (minutes and $\%$ ), and steps for weekdays and weekend. The intensity of weekly PA was assessed as average cpm. The cutoff values used to define the intensity of PA and, therefore, quantify the mean time in each intensity were the following: sedentary time, $\leq 100 \mathrm{cpm}$, light PA, 101-1951 cpm, moderate PA, 1952-5724 cpm, and vigorous PA $\geq 5725$. Moderate-to-vigorous PA was computed by the sum of moderate and vigorous PA.

\section{Statistical procedures}

In this study the sex (male and female) and the quartiles (lower, two middle and upper) of BF and BMI were defined as factors. The quartiles' limits of BF were computed per each sex and for the specific case of this dataset. The anthropometric variables (body mass, height) and PA variables (sedentary, light, moderate, vigorous, in minutes and number of steps) were defined as dependent variables. Comparisons were made by independent t-test (comparison between sexes) and one-way analysis of variance (ANOVA) (between BF and BMI quartiles) after validating normality and homogeneity assumptions. The BF and BMI quartiles represent three categories (lower, middle and upper), thus being factors. The middle group represents two quartiles $\left(2^{\text {nd }}\right.$ and $\left.3^{\text {rd }}\right)$, the lower represents the $1^{\text {st }}$ quartile, and the upper represents the $4^{\text {th }}$ quartile. Effect size (ES) was presented as $\eta^{2}$ for one-way ANOVA and interpreted using the following criteria: no effect $\left(\eta^{2}<0.04\right)$, minimum effect $\left(0.04 \leq \eta^{2}<0.25\right)$, moderate effect $\left(0.25 \leq \eta^{2}<0.64\right)$ and strong effect $\left(\eta^{2} \geq 0.64\right)$ [9]. For the case of the independent t-test, Cohen's $d$ was calculated as ES measured using the following criteria [4]: small effect $(\mathrm{d}<0.2)$; moderate effect $(0.2 \leq \mathrm{d}<0.8)$; and large effect $(\mathrm{d} \geq 0.8)$. Pearson's product moment correlations were calculated in order to examine the association between anthropometric variables (BMI, \%BF) and PA levels (number of steps per day, sedentary time, light PA, moderate PA and vigorous PA). The following correlation scale was adopted [16]: trivial $(\mathrm{r}<0.1)$; small $(0.1 \leq \mathrm{r}<0.3)$; moderate $(0.3 \leq \mathrm{r}<0.5)$; large $(0.5 \leq \mathrm{r}<0.7)$; very large $(0.7 \leq \mathrm{r}<0.9)$; and nearly perfect $(\geq 0.9)$.

Standard multiple linear regression was used to test the hypothesis that female gender and physical activity characteristics can influence the BF and BMI and also was used to test the hypothesis that $\mathrm{BF}$ and $\mathrm{BMI}$ can influence the physical activity characteristics (steps, sedentary, light PA, moderate PA and vigorous PA). First we analysed the assumptions of multiple linear regression. When in the model not all independent variables were a significant predictor we performed stepwise multiple linear regression and 
analysed the assumptions. Standard binary logistic regression was used to test the hypothesis that female gender and physical activity characteristics can influence overweight. First we analysed the assumptions of binary logistic regression. When in the model not all independent variables were a significant predictor we performed binary logistic regression using the forward stepwise method (likelihood ratio) and analysed the assumptions. For all data sets each statistical technique was performed and corresponding assumptions were tested using SPSS software (version 23.0, Chicago, Illinois, USA). Statistical significance was set at $\mathrm{p}=0.05$.

\section{Results}

Anthropometric characteristics and accelerometry data are displayed in Table 1 by sex. Male participants were taller $(7.26 \%)$, heavier $(16.60 \%)$, walked more steps per day $(19.82 \%)$ and spent more time in light PA (4.53\%), moderate PA (24.93\%) and vigorous PA (214.19\%). Female participants had a greater \% of BF $(140.19 \%)$ and spent more time in sedentary behaviour (3.66\%).

Participants were organized according to quartiles (lower, middle and upper) of \% BF. PA levels were then computed and compared per quartile (Table 2). Statistically significant differences in male participants were found in light PA $(p=0.001 ; \mathrm{ES}=0.09)$, moderate PA $(p=0.001$; $\mathrm{ES}=0.042)$ and vigorous $\mathrm{PA}(p=0.001 ; \mathrm{ES}=0.130)$. Post hoc analysis revealed that the middle quartiles spent statistically lower time in light PA, moderate PA and vigorous PA. In the analysis of female participants, a significant difference was found in light PA $(p=0.001$; ES $=0.05)$. In this case, the upper quartile spent statistically more time in light PA than lower and middle quartiles.

The analysis of variance of PA levels between quartiles of BMI can be verified in Table 3. Significant differences were found in male participants between BMI quartiles in light PA $(p=0.002 ; \mathrm{ES}=0.032)$. The middle quartiles spent significantly more time in light PA than the lower and upper quartiles. In the case of female participants, significant differences between BMI quartiles were found in light PA $(p=0.001 ; \mathrm{ES}=0.067)$ and vigorous PA $(p=0.049 ; \mathrm{ES}=0.011)$. The middle quartiles spent statistically more time in light PA and vigorous PA than the lower and upper female quartiles.

Table 4 show the values of Pearson's correlation test between anthropometric variables $(\% \mathrm{BF}, \mathrm{BMI})$ and $\mathrm{PA}$ levels (steps, sedentary, light PA, moderate PA and vigorous PA).

Table 1. Comparison of anthropometric data and PA levels between male and female participants

\begin{tabular}{|c|c|c|c|c|c|c|}
\hline & $\operatorname{Men}(n=53)$ & Women $(n=73)$ & \multirow{3}{*}{$\mathrm{t}$} & \multirow{3}{*}{$\mathrm{df}$} & \multirow{3}{*}{$p$-value } & \multirow{3}{*}{ Cohen's d (ES) } \\
\hline & $\mathrm{M} \pm \mathrm{SD}$ & $\mathrm{M} \pm \mathrm{SD}$ & & & & \\
\hline & [CI 95\%] & [CI 95\%] & & & & \\
\hline Height $[\mathrm{cm}]$ & $\begin{array}{c}176.66 \pm 7.20 \\
{[175.93-177.40]}\end{array}$ & $\begin{array}{c}164.71 \pm 6.59 \\
{[164.14-165.29]}\end{array}$ & 25.21 & 754.41 & 0.001 & $\begin{array}{c}1.74 \\
\text { Large effect }\end{array}$ \\
\hline Body mass $[\mathrm{kg}]$ & $\begin{array}{l}71.52 \pm 10.60 \\
{[70.43-72.60]}\end{array}$ & $\begin{array}{l}61.34 \pm 10.24 \\
{[60.45-62.23]}\end{array}$ & 14.36 & 880 & 0.001 & $\begin{array}{c}0.98 \\
\text { Large effect }\end{array}$ \\
\hline $\mathrm{BMI}\left[\mathrm{kg} \cdot \mathrm{m}^{-2}\right]$ & $\begin{array}{c}22.57 \pm 2.66 \\
{[22.30-22.84]}\end{array}$ & $\begin{array}{c}22.64 \pm 3.56 \\
{[22.33-22.95]}\end{array}$ & -0.298 & 879.31 & 0.766 & $\begin{array}{c}-0.02 \\
\text { Small effect }\end{array}$ \\
\hline Body Fat Mass $[\% \mathrm{BF}]$ & $\begin{array}{l}10.30 \pm 4.56 \\
{[9.84-10.77]}\end{array}$ & $\begin{array}{c}24.74 \pm 7.49 \\
{[24.09-25.39]}\end{array}$ & -35.45 & 856.25 & 0.001 & $\begin{array}{c}-2.25 \\
\text { Large effect }\end{array}$ \\
\hline Steps [number per day] & $\begin{array}{c}10002.15 \pm 7628.44 \\
{[9223.36-10780.94]}\end{array}$ & $\begin{array}{l}8347.51 \pm 3994.70 \\
{[8000.34-8694.69]}\end{array}$ & 3.815 & 517.12 & 0.001 & $\begin{array}{c}0.29 \\
\text { Moderate effect }\end{array}$ \\
\hline Sedentary time $[\mathrm{min} /$ day $]$ & $\begin{array}{l}741.01 \pm 189.89 \\
{[721.63-760.40]}\end{array}$ & $\begin{array}{l}768.11 \pm 156.38 \\
{[754.52-781.11]}\end{array}$ & -2.25 & 700.82 & 0.025 & $\begin{array}{c}-0.16 \\
\text { Small effect }\end{array}$ \\
\hline Light PA [min/day] & $\begin{array}{l}298.70 \pm 107.09 \\
{[287.77-309.63]}\end{array}$ & $\begin{array}{c}285.76 \pm 81.93 \\
{[278.65-292.89]}\end{array}$ & 1.95 & 664.25 & 0.052 & $\begin{array}{c}0.14 \\
\text { Small effect }\end{array}$ \\
\hline Moderate PA [min/day] & $\begin{array}{l}54.27 \pm 42.85 \\
{[49.89-58.64]}\end{array}$ & $\begin{array}{l}43.44 \pm 33.57 \\
{[40.52-46.36]}\end{array}$ & 4.05 & 675.88 & 0.001 & $\begin{array}{c}0.29 \\
\text { Moderate effect }\end{array}$ \\
\hline Vigorous PA [min/day] & $\begin{array}{l}4.65 \pm 8.01 \\
{[3.83-5.46]}\end{array}$ & $\begin{array}{l}1.48 \pm 3.67 \\
{[1.16-1.80]}\end{array}$ & 7.09 & 483.32 & 0.001 & $\begin{array}{c}0.54 \\
\text { Moderate effect }\end{array}$ \\
\hline
\end{tabular}


Table 2. Accelerometer data in men and women with valid registrations, organized according to quartiles (lower, two middle and upper) of $\% \mathrm{BF}$

\begin{tabular}{|c|c|c|c|c|c|c|}
\hline $\operatorname{Men}(n=53)$ & $\begin{array}{l}\text { Lower }<6.5 \% \\
\quad(n=13)\end{array}$ & $\begin{array}{l}\text { Middle } 6.5-12.8 \% \\
\qquad(\mathrm{n}=27)\end{array}$ & $\begin{array}{l}\text { Upper } 12.8 \% \\
(\mathrm{n}=13)\end{array}$ & $\mathrm{F}$ & $p$-value & Eta square (ES) \\
\hline Sedentary time [min/day] & $\begin{array}{l}737.63 \pm 174.16 \\
{[699.85-775.42]}\end{array}$ & $\begin{array}{c}743.50 \pm 187.85 \\
{[717.03-769.96]}\end{array}$ & $\begin{array}{l}738.79 \pm 209.28 \\
{[695.21-782.38]}\end{array}$ & 0.036 & 0.965 & $\begin{array}{c}0.001 \\
\text { No effect }\end{array}$ \\
\hline Light PA [min/day] & $\begin{array}{c}313.86 \pm 100.33 \\
{[292.08-335.63]^{b}}\end{array}$ & $\begin{array}{c}270.20 \pm 100.90 \\
{[255.98-284.41]^{\mathrm{a}, \mathrm{c}}}\end{array}$ & $\begin{array}{c}346.09 \pm 107.46 \\
{[323.71-368.47]^{\mathrm{a}}}\end{array}$ & 18.25 & 0.001 & $\begin{array}{c}0.09 \\
\text { Minimum effect }\end{array}$ \\
\hline Moderate PA [min/day] & $\begin{array}{c}68.46 \pm 44.44 \\
{[58.82-78.11]^{\mathrm{b}}}\end{array}$ & $\begin{array}{c}46.78 \pm 39.90 \\
{[41.16-52.40]^{\mathrm{a}}}\end{array}$ & $\begin{array}{l}57.30 \pm 44.26 \\
{[48.08-66.51]}\end{array}$ & 8.14 & 0.001 & $\begin{array}{c}0.042 \\
\text { Minimum effect }\end{array}$ \\
\hline Vigorous PA [min/day] & $\begin{array}{c}9.80 \pm 11.54 \\
{[7.29-12.30]^{b, c}}\end{array}$ & $\begin{array}{c}2.59 \pm 4.77 \\
{[1.91-3.26]^{\mathrm{a}}}\end{array}$ & $\begin{array}{c}4.33 \pm 7.57 \\
{[2.75-5.91]^{\mathrm{a}}} \\
\end{array}$ & 27.34 & 0.001 & $\begin{array}{c}0.130 \\
\text { Moderate effect }\end{array}$ \\
\hline Women $(n=73)$ & $\begin{array}{l}\text { Lower }<18.6 \% \\
\quad(\mathrm{n}=13)\end{array}$ & $\begin{array}{l}\text { Middle } 18.6-29.4 \% \\
\quad(\mathrm{n}=27)\end{array}$ & $\begin{array}{l}\text { Upper } 29.4 \% \\
(\mathrm{n}=13)\end{array}$ & $\mathrm{F}$ & p-value & Eta square (ES) \\
\hline Sedentary time [min/day] & $\begin{array}{c}777.58 \pm 155.42 \\
{[748.48-806.68]}\end{array}$ & $\begin{array}{c}762.75 \pm 157.92 \\
{[743.69-781.82]}\end{array}$ & $\begin{array}{c}770.86 \pm 154.82 \\
{[744.31-797.42]}\end{array}$ & 0.38 & 0.683 & $\begin{array}{c}0.001 \\
\text { No effect }\end{array}$ \\
\hline Light PA [min/day] & $\begin{array}{c}270.90 \pm 80.08 \\
{[255.91 \pm 285.90]^{\mathrm{c}}}\end{array}$ & $\begin{array}{c}276.70 \pm 78.17 \\
{[267.26-286.13]^{\mathrm{c}}}\end{array}$ & $\begin{array}{c}316.42 \pm 83.50 \\
{[302.10-330.74]^{\mathrm{a}, \mathrm{b}}}\end{array}$ & 13.41 & 0.001 & $\begin{array}{c}0.05 \\
\text { Minimum effect }\end{array}$ \\
\hline Moderate PA [min/day] & $\begin{array}{c}39.82 \pm 25.35[35.08 \\
-44.57]\end{array}$ & $\begin{array}{l}43.95 \pm 34.78 \\
{[39.75-48.15]}\end{array}$ & $\begin{array}{l}45.46 \pm 37.02 \\
{[39.11-51.81]}\end{array}$ & 0.92 & 0.399 & $\begin{array}{c}0.004 \\
\text { No effect }\end{array}$ \\
\hline Vigorous PA [min/day] & $\begin{array}{c}1.45 \pm 3.92 \\
{[0.71-2.18]}\end{array}$ & $\begin{array}{l}1.35 \pm 3.38 \\
{[0.95-1.75]}\end{array}$ & $\begin{array}{l}1.77 \pm 4.17 \\
{[1.06-2.49]}\end{array}$ & 0.60 & 0.550 & $\begin{array}{c}0.002 \\
\text { No effect }\end{array}$ \\
\hline
\end{tabular}

Significantly different compared with Lower ${ }^{\mathrm{a}}$; Middle ${ }^{\mathrm{b}}$; and Upperc at $\mathrm{p}<0.05$

Table 3. Accelerometer data in men and women with valid registrations, organized according to quartiles (lower, two middle and upper) of BMI

\begin{tabular}{|c|c|c|c|c|c|c|}
\hline $\operatorname{Men}(n=53)$ & $\begin{array}{l}\text { Lower }<25 \\
(\mathrm{n}=16)\end{array}$ & $\begin{array}{l}\text { Middle } 25-30 \\
\quad(\mathrm{n}=26)\end{array}$ & $\begin{array}{l}\text { Upper }>30 \\
(\mathrm{n}=11)\end{array}$ & $\mathrm{F}$ & $p$-value & Eta square (ES) \\
\hline Sedentary time [min/day] & $\begin{array}{l}739.67 \pm 184.46 \\
{[719.66-759.67]}\end{array}$ & $\begin{array}{l}752.57 \pm 243.03 \\
{[669.09-836.06]}\end{array}$ & $\begin{array}{c}746.57 \pm 167.24 \\
{[591.90-901.24]}\end{array}$ & 0.76 & 0.927 & $\begin{array}{c}0.001 \\
\text { No effect }\end{array}$ \\
\hline Light PA [min/day] & $\begin{array}{c}291.85 \pm 99.70 \\
{[281.03-302.66] \mathrm{b}}\end{array}$ & $\begin{array}{c}353.86 \pm 135.22 \\
{[307.41-400.31] \mathrm{a}}\end{array}$ & $\begin{array}{l}345.00 \pm 193.13 \\
{[166.39-523.61]}\end{array}$ & 6.14 & 0.002 & $\begin{array}{c}0.032 \\
\text { No effect }\end{array}$ \\
\hline Moderate PA [min/day] & $\begin{array}{l}55.40 \pm 42.93 \\
{[50.69-60.01]}\end{array}$ & $\begin{array}{l}49.77 \pm 44.17 \\
{[34.60-64.94]}\end{array}$ & $\begin{array}{c}28.86 \pm 18.40 \\
{[8.86-42.86]}\end{array}$ & 1.844 & 0.160 & $\begin{array}{c}0.010 \\
\text { No effect }\end{array}$ \\
\hline Vigorous PA [min/day] & $\begin{array}{l}4.84 \pm 8.05 \\
{[3.96-5.71]}\end{array}$ & $\begin{array}{l}3.74 \pm 8.26 \\
{[0.90-6.58]}\end{array}$ & $\begin{array}{c}0.29 \pm 0.76 \\
{[0-0.98]}\end{array}$ & 1.355 & 0.259 & $\begin{array}{c}0.007 \\
\text { No effect }\end{array}$ \\
\hline Women $(\mathrm{n}=73)$ & $\begin{array}{c}\text { Lower }<25 \\
(\mathrm{n}=15)\end{array}$ & $\begin{array}{l}\text { Middle } 25-30 \\
\quad(\mathrm{n}=24)\end{array}$ & $\begin{array}{c}\text { Upper }>30 \\
(\mathrm{n}=14)\end{array}$ & $\mathrm{F}$ & p-value & Eta square (ES) \\
\hline Sedentary time $[\mathrm{min} /$ day $]$ & $\begin{array}{l}772.05 \pm 159.04 \\
{[756.66-787.43]}\end{array}$ & $\begin{array}{c}754.85 \pm 138.24 \\
{[724.85-784.85]}\end{array}$ & $\begin{array}{c}731.71 \pm 180.90 \\
{[627.27-836.16]}\end{array}$ & 0.812 & 0.445 & $\begin{array}{c}0.003 \\
\text { No effect }\end{array}$ \\
\hline Light PA [min/day] & $\begin{array}{c}275.50 \pm 78.23 \\
{[267.93-283.6] \mathrm{b}}\end{array}$ & $\begin{array}{c}331.51 \pm 85.40 \\
{[312.98-350.04] \mathrm{a}}\end{array}$ & $\begin{array}{c}314.21 \pm 71.10 \\
{[273.16-355.27]}\end{array}$ & 18.353 & 0.001 & $\begin{array}{c}0.067 \\
\text { Minimum effect }\end{array}$ \\
\hline Moderate PA [min/day] & $\begin{array}{l}42.20 \pm 31.94 \\
{[39.11-45.29]}\end{array}$ & $\begin{array}{l}49.96 \pm 40.88 \\
{[41.09-58.84]}\end{array}$ & $\begin{array}{l}40.71 \pm 29.70 \\
{[23.56-57.87]}\end{array}$ & 1.919 & 0.148 & $\begin{array}{c}0.008 \\
\text { No effect }\end{array}$ \\
\hline Vigorous PA [min/day] & $\begin{array}{c}1.38 \pm 3.42 \\
{[1.05-1.71] \mathrm{c}} \\
\end{array}$ & $\begin{array}{r}2.21 \pm 4.88 \\
{[1.15-3.27] \mathrm{c}} \\
\end{array}$ & $\begin{array}{l}0.07 \pm 0.27 \\
{[0-0.23] \mathrm{a}, \mathrm{b}}\end{array}$ & 2.885 & 0.049 & $\begin{array}{c}0.011 \\
\text { No effect }\end{array}$ \\
\hline
\end{tabular}


Table 4. Pearson's correlation test between anthropometrics and PA levels

\begin{tabular}{lccccc}
\hline & Steps & Sedentary & Light PA & Moderate PA & Vigorous PA \\
\hline \multirow{2}{*}{ Body Fat mass (BF) } & $-0.122^{* *}$ & $0.079^{*}$ & 0.058 & -0.117 & $-0.259^{* *}$ \\
& Small correlation & Trivial correlation & Trivial correlation & Small correlation & Small correlation \\
\hline \multirow{2}{*}{ BMI } & 0.048 & 0.040 & $0.253^{* *}$ & 0.029 & -0.051 \\
& Trivial correlation & Trivial correlation & Small correlation & Trivial correlation & Trivial correlation \\
\hline
\end{tabular}

*p-value $<0.05 ; * *$ p-value $<0.01$

Standard multiple linear regression was used to test the hypothesis that female sex and PA characteristics can influence the BF and BMI (Table 5). Female sex and PA characteristics explained $57.10 \%$ of $\mathrm{BF}$ variation and the model was statistically significant $\left(F_{(6,875)}=196.38\right.$; $p=0.001)$. Female sex, light PA and vigorous PA were revealed to be significant predictors of $\mathrm{BF}$ variation. In $B M I$,

Table 5. Standard multiple linear regression (method: Enter)

\begin{tabular}{lcc}
\hline & \multicolumn{2}{c}{$\begin{array}{c}\text { Dependent variables } \\
\text { (unstandardized } \beta \text { and significance ) }\end{array}$} \\
\hline Model & BF & BMI \\
(Constant) & 6.601 & 19.379 \\
Sex (Female) & $14.113^{*}$ & 0.012 \\
Steps & 0.0001 & -0.000023 \\
Sedentary & 0.001 & 0.001 \\
LightPA & $0.014^{*}$ & $0.010^{*}$ \\
ModeratePA & 0.006 & 0.001 \\
VigorousPA & $-0.119^{*}$ & -0.040 \\
R $^{2}$ & 0.574 & 0.075 \\
Adjusted R & 0.571 & 0.069 \\
\hline
\end{tabular}

$*-p<0.008$

Table 6. Multiple linear regression (method: Stepwise)

\begin{tabular}{lcc}
\hline & \multicolumn{2}{c}{$\begin{array}{c}\text { Dependent variables } \\
\text { (unstandardized } \beta \text { and significance ) }\end{array}$} \\
\hline Model & BF & BMI \\
(Constant) & 7.262 & 20.081 \\
Sex (Female) & $14.144^{*}$ & - \\
LightPA & $0.012^{*}$ & $0.009 * *$ \\
VigorousPA & $-0.143 *$ & $-0.048^{* *}$ \\
$\mathrm{R}^{2}$ & 0.572 & 0.072 \\
Adjusted $\mathrm{R}^{2}$ & 0.57 & 0.07 \\
\hline
\end{tabular}

${ }^{*}$ - $p$-value $<0.017 ;{ }^{* *}-p<0.025$ the results showed that female sex and PA characteristics explained $6.9 \%$ of the variation and the model was statistically significant $\left(F_{(6,875)}=11.902 ; p=0.001\right)$. Light PA was found to be a significant predictor of this variable.

According to the stepwise multiple linear regression (Table 6), female sex, light PA and vigorous PA explained $\sim 57 \%$ of BF variation and the model was statistically significant $\left(F_{(3,878)}=390.639 ; p=0.001\right)$. In $B M I$, the results showed that light PA and vigorous PA explained $\sim 7 \%$ of the variation and the model was statistically significant $\left(F_{(2,879)}=34.166 ; p=0.001\right)$.

Standard multiple linear regression was used to test the hypothesis that BF and BMI could influence PA characteristics (steps, sedentary, light PA, moderate PA and vigorous PA) (Table 7). BF and BMI explained 3.1\% of steps variation and the model was statistically significant $\left(F_{(2,879)}=15.054 ; p=0.001\right)$. In sedentary time, the results showed that $\mathrm{BF}$ and $\mathrm{BMI}$ explained $0.4 \%$ of the variation and the model was not statistically significant $\left(F_{(2,879)}=2.757 ; p=0.064\right)$. In light PA, the results showed that $\mathrm{BF}$ and $\mathrm{BMI}$ accounted for $7.1 \%$ of the variation and the model was statistically significant $\left(F_{(2,879)}=34.485\right.$; $p=0.001)$. In light $\mathrm{PA}$, the results showed that $\mathrm{BF}$ and BMI explained $7.1 \%$ of the variation and the model was statistically significant $\left(F_{(2,879)}=34.485 ; p=0.001\right)$. In moderate PA, the results showed that BF and BMI accounted for $2.3 \%$ of the variation and the model was statistically significant $\left(F_{(2,879)}=11.493 ; p=0.001\right)$. In vigorous PA, the results showed that BF and BMI explained $7.6 \%$ of the variation and the model was statistically significant $\left(F_{(2,879)}=37.365 ; p=0.001\right)$.

Standard binary logistic regression was used to test the hypothesis that female sex and PA characteristics could influence overweight (Table 8). The full model containing all predictors was statistically significant $\left(G^{2}(6)=58.598\right.$; $p=0.001$ ), indicating that the model was able to distinguish between overweight and not overweight. The Hosmer-Lemeshow test indicated support for the model $\left(X^{2}=13.2 ; p=0.105\right)$. The model as a whole explained between $6.4 \%$ (Cox and Snell $\mathrm{R}^{2}$ ), 11\% (Nagelkerke $\mathrm{R}^{2}$ ) and $7.6 \%\left(\right.$ McFadden $\mathrm{R}^{2}$ ) of the variance in overweight status, and correctly classified $84.1 \%$ of cases. The sensitivity and specificity of the model are, respectively, $5 \%$ and $99.5 \%$. 
Table 7. Standard multiple linear regression (method: Enter)

\begin{tabular}{|c|c|c|c|c|c|}
\hline \multirow[b]{2}{*}{ Model } & \multicolumn{5}{|c|}{$\begin{array}{c}\text { Dependent variables } \\
\text { (unstandardized } \beta \text { and significance ) }\end{array}$} \\
\hline & Steps & Sedentary & Light PA & Moderate PA & Vigorous PA \\
\hline (Constant) & 4774.103 & 734.491 & 105.239 & 27.053 & 1.323 \\
\hline Body Fat mass (BF) & $-127.283^{*}$ & 1.450 & $-1.086^{*}$ & $-0.741 *$ & $-0.208 *$ \\
\hline BMI & $293.921 *$ & -0.215 & $9.122 *$ & $1.538^{*}$ & $0.237 *$ \\
\hline $\mathrm{R}^{2}$ & 0.033 & 0.004 & 0.073 & 0.023 & 0.078 \\
\hline Adjusted $\mathrm{R}^{2}$ & 0.031 & 0.006 & 0.071 & 0.025 & 0.076 \\
\hline
\end{tabular}

$*-p<0.025$

Table 8. Logit coefficients of standard binary logistic regression of the dependent variable overweight

\begin{tabular}{|c|c|c|c|c|c|c|c|c|}
\hline \multirow{2}{*}{$\begin{array}{l}\text { Independent } \\
\text { variables }\end{array}$} & \multirow{2}{*}{ B } & \multirow{2}{*}{ S.E. } & \multirow{2}{*}{$X_{\text {Wald }}^{2}$} & \multirow{2}{*}{ df } & \multirow{2}{*}{$p$-value } & \multirow{2}{*}{$\begin{array}{c}\operatorname{Exp}(\mathrm{B}) \\
\text { (odds ratios) }\end{array}$} & \multicolumn{2}{|c|}{$95 \% \mathrm{CI}$ for $\operatorname{EXP}(\mathrm{B})$} \\
\hline & & & & & & & Lower & Upper \\
\hline Steps & 0.000 & 0.000 & 4.577 & 1 & 0.032 & 1.000 & 1.000 & 1.000 \\
\hline Sedentary & 0.000 & 0.001 & 0.111 & 1 & 0.739 & 1.000 & 0.999 & 1.001 \\
\hline LightPA & 0.008 & 0.001 & 40.830 & 1 & 0.000 & 1.008 & 1.006 & 1.011 \\
\hline ModeratePA & 0.009 & 0.006 & 2.245 & 1 & 0.134 & 1.009 & 0.997 & 1.021 \\
\hline VigorousPA & 0.004 & 0.021 & 0.033 & 1 & 0.856 & 1.004 & 0.964 & 1.045 \\
\hline Sex (Female) & 0.735 & 0.217 & 11.486 & 1 & 0.001 & 2.085 & 1.363 & 3.189 \\
\hline Constant & -3.849 & 0.663 & 33.653 & 1 & 0.000 & 0.021 & & \\
\hline
\end{tabular}

As shown in Table 8, only three of the independent variables made a unique statistically significant contribution to the model (female sex, light PA and steps).

After performing the binary logistic regression using the forward stepwise method (likelihood ratio), the new model containing only the predictors light PA $(\mathrm{B}=0.006$; $X_{\text {Wald }}^{2}(1)=40.611 ; p=0.001 ; \mathrm{OR}=1.006(95 \% \mathrm{CI}$ (1.004-1.008) ) and female sex $\left(\mathrm{B}=0.805 ; X^{2}{ }_{\text {Wald }}(1)=14.78\right.$; $p=0.001 ; \mathrm{OR}=2.236(95 \% \mathrm{CI}(1.484-3.370))$ was statistically significant $\left(G^{2}(2)=52.349 ; p=0.001\right)$, indicating that the model was able to distinguish between overweight and not overweight. The Hosmer-Lemeshow test indicated support for the model $\left(X^{2}(8)=13.79 ; p=0.087\right)$. The model as a whole explained between 5.8\% (Cox and Snell $\mathrm{R}^{2}$ ), 9.9\% (Nagelkerke $\mathrm{R}^{2}$ ) and $9.22 \%\left(\right.$ McFadden $\mathrm{R}^{2}$ ) of the variance in overweight status, and correctly classified $84.2 \%$ of cases. The sensitivity and specificity of the model are, respectively, $2.1 \%$ and $99.7 \%$. The area under the ROC curve is $\mathrm{c}=0.686$ $(p=0.001)$, which can be interpreted to mean that a randomly selected individual from the overweight group has a test value larger than that for a randomly chosen individual from the not overweight group $68.6 \%$ of the time.

In Figure 1 it can be seen that, for the same light PA, the probability of a female being overweight is much higher than the probability of a male being overweight.

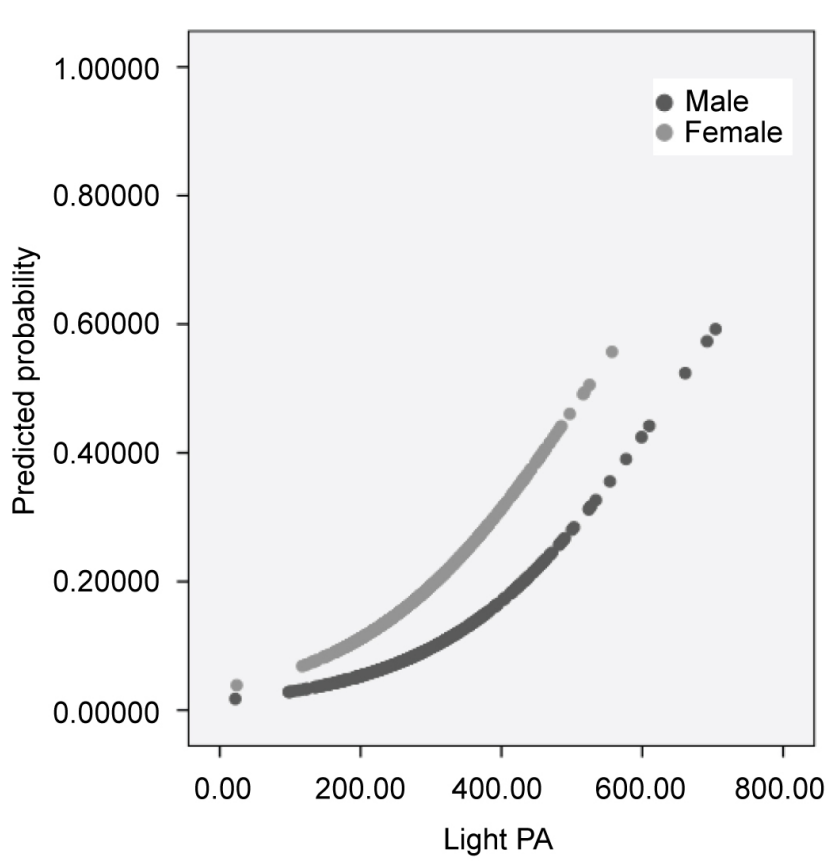

Fig. 1. Probability of female and male participants being overweight 


\section{Discussion}

This study aimed to analyse the association between anthropometric characteristics and PA levels of university students. A further aim was to analyse the variance of PA levels between quartiles of $\mathrm{BF}$ and $\mathrm{BMI}$. The main results revealed that PA patterns can explain $57.9 \%$ of the $\mathrm{BF}$, although PA only may explain $6.9 \%$ of BMI. Particularly, light PA was found to be a significant predictor of the BF dimension. In the other hand, standard multiple linear regression was used to test the hypothesis that BF and BMI can influence the PA levels and the results revealed that the time in vigorous PA can explain $7.6 \%$ of the variance in both anthropometric variables. The analysis of variance between BF quartiles showed statistically significant differences in male participants in light PA, moderate PA and vigorous $\mathrm{PA}$. The variance between $\mathrm{BMI}$ quartiles revealed significant differences between BMI quartiles in light PA and vigorous PA of female participants.

Some studies have linked PA with healthy behaviours of children, adults and the elderly [1, 27, 28]. As far we know, no longitudinal study that analysed the effects of PA in health parameters has reported negative results over time [23]. Daily PA levels have been negatively related to the body mass gain over the years $[12,22,25]$ and the incident risk of type 2 diabetes mellitus [25]. Moreover, PA is associated with decreased rates of coronary heart disease [3]. Such evidence seems to highlight the importance of daily PA to ensure good health and quality of life. Based on that, this study analysed the effects of PA on the body composition of young adults studying in a university environment.

The rationale to study university students is the great change in life style and the critical period that they experience after finishing high school $[8,13]$. The standard multiple linear regression for female sex (dummy variable) revealed that light PA and vigorous PA were significant predictors of BF, thus suggesting that being active or inactive may be associated with changes of body composition that conversely may lead to a healthy or non-healthy status. The American College of Sports Medicine highlights that light PA is not enough to prevent overweight, thus suggesting cardiorespiratory exercise at moderateto-vigorous intensity for $150 \mathrm{~min}$ per week, at least [19]. In female participants, the analysis per BF quartile only revealed significant differences in light PA. Surprisingly, the upper group of $\mathrm{BF}(>29.4 \% \mathrm{BF}$ in females) spent significantly greater time in light PA than middle and lower quartiles. In the case of male participants, the analysis of variance between quartiles of $\mathrm{BF}$ revealed that the upper limit ( $>12.8 \%$ BF) had significantly lower levels of light $\mathrm{PA}$, moderate PA and vigorous PA time per day than the lower limit $(<6.5 \% \mathrm{BF})$. Interestingly, the upper group had greater values of activity than the middle group. Such a result may be justified by the fact that the middle group represents two quartiles ( $2^{\text {nd }}$ and $3^{\text {rd }}$ ) and such a methodological decision may have covered the evidence. Another explanation could be the Hawthorne effect that may have occurred in the upper group since they only wore the accelerometer for one week.

The lack of significant results in the analysis of variance of PA levels between quartiles of BF and BMI may be explained by the worse Hawthorne effect (reactivity to their awareness of being observed). Some participants may have been more active than normal, thus influencing the results. On the other hand, an interesting and singular study that tracked the long-term effect of leisure time PA in 3653 women and 2626 men revealed that the results did not support the fact that medium or high PA at baseline prevents obesity in the long term [20]. In fact, the authors suggested that among the more active subjects there were more obese ones later on [20]. Despite the small and nonusual evidence, our results suggested a balanced bias in PA levels of different groups of BF and BMI.

Besides the association of PA levels to explain BF and $\mathrm{BMI}$, a reverse analysis tried to analyse whether BF and BMI can explain the PA levels (based on sociocultural and psychological engagement). For the dummy variable of female sex, the results revealed that BF and BMI explained $7.1 \%$ of the variance in light PA, $2.3 \%$ of moderate PA and $7.6 \%$ of vigorous PA. Therefore, it is possible that body composition may constrain PA levels. Thus such a hypothesis must be considered in future studies: Is it the body composition that influences physical activity, or vice versa? We found no studies that analysed the psychological conditions that associate the body image with the pursuit of an active life style in university studies. This should be considered in future studies. Finally, the model that used light PA was able to predict overweight in university students $(\mathrm{BMI}>25)$ with a rate of $84 \%$, thus suggesting that the time spent in light activities may be crucial to a healthy life style [14].

Finally, analysis of variance revealed significant differences in body composition and PA patterns between sexes. It was observed that males are significantly more active than females, especially doing more moderate-to-vigorous activities. On the other hand, females were significantly more sedentary and revealed significantly greater values of BF but not BMI. Our results are in line with previous studies that showed higher PA levels of men in comparison with women $[2,4]$. The differences in BF are normal considering the specific composition of men and women and the differences in fat metabolism [3]. Such results may be used to define some different interventions taking into account the specificities of each sex.

This study had some limitations. The use of accelerometers for only 7 consecutive days may have contributed 
to the occurrence of the Hawthorne effect, particularly in groups in upper limits of BF and BMI. An extended period up to four weeks may help to avoid this problem in future studies. Another limitation of this study was that some of the participants were sports students or amateur athletes (26.19\%), thus increasing the PA patterns in some of them, even in students with greater values of BF or BMI. Future studies should consider not including these particular groups to test the homogeneity of the sample. Finally, this study did not use the most precise and up-to-date devices to test BF. Dual-energy X-ray absorptiometry or air displacement plethysmography technology would be more accurate methods to determine BF than electronic scales. Nevertheless, despite the bioelectrical impedance analysis used in this study not being the most appropriate choice for body composition measurement, the appropriate algorithms for the population can accurately measure BF [6].

\section{Translation to health education practice}

The results obtained from this study suggest that light PA may predict the overweight participants. Moreover, PA levels may explain more than $50 \%$ of the $\mathrm{BF}$ variation, thus suggesting that activity patterns should be considered in health programmes and government policies to prevent and reduce overweight and obesity. Future studies should consider adopting a longitudinal study with objective measurement of PA, trying to identify the adaptations to specific critical periods such as the first job, the family constitution or the adaptation to become a mother or father. Should PA levels in university students determine the style of life in older stages? May PA patterns across life determine the anthropometrics and occurrence of diseases? These research questions can be the next step to follow after our study.

\section{Conclusions}

The results of this study indicate that PA levels of university students may predict BF and BMI. Moreover, light PA was found to be a predictor of overweight participants. Both results confirm that PA and anthropometric characteristics are associated and should be considered to prevent obesity. On the other hand, the analysis of variance between BF and BMI quartiles also revealed that PA could not be the only contributing factor to reduce obesity and overweight in young adults. This study concludes that body composition can be influenced by PA levels and for that reason specific programmes of exercise must be adopted by government policies to promote a healthy life style in young adults. Future studies should consider following up the population across different stages of their life span and organize different experimental groups with diverse PA levels, nutritional control and other interventions that complement the benefits of PA and exercise.
Conflict of interest: Authors state no conflict of interest.

\section{References}

1. Arias-Palencia N.M., Solera-Martínez M., Gracia-Marco L., Silva P., Martínez-Vizcaíno V., Cańete-GarcíaPrieto J., Sánchez-López M. (2015) Levels and patterns of objectively assessed physical activity and compliance with different public health guidelines in university students. PLoS One 10: e0141977. DOI: 10.1371/journal. pone.0141977.

2. Azevedo M.R., Araújo C.L.P., Reichert F.F., Siqueira F.V., da Silva M.C., Hallal P.C. (2007) Gender differences in leisure-time physical activity. Int. J. Public. Health, 52: 8-15. DOI: 10.1007/s00038-006-5062-1.

3. Blaak E. (2001) Gender differences in fat metabolism. Curr. Opin. Clin. Nutr. Metab. Care, 4: 499-502.

4. Brook J.S., Lee J.Y., Brook D.W., Finch S.J. (2013) Determinants of obesity: Results from a longitudinal study of adolescents and adults living in an Urban area. Psychol. Rep., 113: 717-733. DOI: abs/10.2466/15.13. PR0.113x26z6.

5. Burton N.W. Turrell G. (2000) Occupation, hours worked, and leisure-time physical activity. Prev. Med. (Baltim), 31: 673-681. Available from: http://linkinghub.elsevier. com/retrieve/pii/S0091743500907631

6. Chomistek A.K., Chasman D.I., Cook N.R., Rimm E.B., Lee I.-M. (2013) Physical activity, Genes for physical fitness, and risk of coronary heart disease. Med. Sci. Sport Exerc., 45: 691-697. Available from: http://content. wkhealth.com/linkback/openurl?sid=WKPTLP:landingp age\&an=00005768-201304000-00011.

7. Cohen J. (1988) Statistical power analysis for the behavioral sciences. Hillsdale, NJ: Lawrence Erlbaum Associates.

8. Colman I., Zeng Y., McMartin S.E., Naicker K., Ataullahjan A., Weeks M., Senthilselvan A., Galambos N.L. (2014) Protective factors against depression during the transition from adolescence to adulthood: Findings from a national Canadian cohort. Prev. Med. (Baltim), 65: 28-32. Available from: http://linkinghub.elsevier.com/retrieve/pii/S0091743514001315.

9. Dehghan M. Merchant A.T. (2008) Is bioelectrical impedance accurate for use in large epidemiological studies? Nutr. J., 7: 26. Available from: http://www.nutritionj. com/content/7/1/26.

10. Dinger M.K. Behrens T.K. (2006) Accelerometer-determined physical activity of free-living college students. Med. Sci. Sport Exerc., 38: 774-779. Available from: http://content.wkhealth.com/linkback/openurl?sid=WKP TLP:landingpage\&an=00005768-200604000-00024.

11. Fedewa M.V., Das B.M., Evans E.M., Dishman R.K. (2014) Change in weight and adiposity in college students. 
Am. J. Prev. Med., 47: 641-652.Available from: http://linkinghub.elsevier.com/retrieve/pii/S0749379714004024.

12. Ferguson C.J. (2009) An effect size primer: A guide for clinicians and researchers. Prof. Psychol. Res. Pract., 40: 532-538.

13. Gokee-LaRose J., Gorin A.A., Raynor H.A., Laska M.N., Jeffery R.W., Levy R.L., Wing R.R. (2009) Are standard behavioral weight loss programs effective for young adults? Int. J. Obes., 33: 1374-1380. DOI: 10.1038/ ijo.2009.185.

14. González Sandoval C.E., Díaz Burke Y., MendizabalRuiz A.P., Medina Díaz E., Alejandro Morales J. (2014) Prevalence of obesity and altered lipid profile in university students. Nutr. Hosp., 29: 315-321.

15. Gordon-Larsen P., Hou N., Sidney S., Sternfeld B., Lewis C.E., Jacobs D.R., Popkin B.M. (2008) Fifteenyear longitudinal trends in walking patterns and their impact on weight change. Am. J. Clin. Nutr., 89: 19-26. DOI: 10.3945/ajcn.2008.26147.

16. Gropper S.S., Simmons K.P., Connell L.J., Ulrich P.V. (2012) Changes in body weight, composition, and shape: a 4-year study of college students. Appl. Physiol. Nutr. Metab., 37: 1118-1123. DOI: abs/10.1139/h2012-139.

17. Haskell W.L., Lee I.M., Pate R.R., Powell K.E., Blair S.N., Franklin B.A., Macera C.A., Heath G.W., Thompson P.D., Bauman A. (2007) Physical activity and public health. Med. Sci. Sport Exerc., 39: 1423-1434. Available from: http://content.wkhealth.com/linkback/openurl?sid=WKP TLP:landingpage\&an=00005768-200708000-00027.

18. Hebden L., Chan H.N., Louie J.C., Rangan A., AllmanFarinelli M. (2015) You are what you choose to eat: factors influencing young adults' food selection behaviour. J. Hum. Nutr. Diet., 28: 401-408. DOI: 10.1111/ jhn. 12312.

19. Hopkins K.D., Hopkins B.R., Glass G.V. (1996) Basic statistics for the behavioral sciences. Boston: Allyn and Bacon.

20. Kim van N.A., Larson N., Laska M.N. (2012) Emerging adulthood: A critical age for preventing excess weight gain? Adolesc. Med. State. Art. Rev., 23: 571-588.

21. Maher J.P., Pincus A.L., Ram N., Conroy D.E. (2015) Daily physical activity and life satisfaction across adulthood. Dev. Psychol., 51: 1407-1419. DOI: 10.1037/ $\operatorname{dev} 0000037$.

22. Pescatello L.S., Arena R., Riebe D., Kluwer P.D.T.W. (2014) ACSM's Guidelines for Exercise Testing and Prescription. Philadelphia, PA, USA: Lippincott Williams \& Wilkins.

23. Petersen L., Schnohr P., Srrrensen T.I.A. (2004) Longitudinal study of the long-term relation between physical activity and obesity in adults. Int. J. Obes., 28: 105-112. DOI: $10.1038 /$ sj.ijo.0802548.
24. Peterson N.E., Sirard J.R., Kulbok P.A., DeBoer M.D., Erickson J.M. (2015) Validation of accelerometer thresholds and inclinometry for measurement of sedentary behavior in young adult university students. Res. Nurs. Health, 38: 492-499. DOI: 10.1002/nur.21694.

25. Di Pietro L., Dziura J., Blair S.N. (2004) Estimated change in physical activity level (PAL) and prediction of 5-year weight change in men: the Aerobics Center Longitudinal Study. Int. J. Obes., 28: 1541-1547. DOI: 10.1038/sj.ijo.0802821.

26. Rauner A., Mess F., Woll A. (2013) The relationship between physical activity, physical fitness and overweight in adolescents: a systematic review of studies published in or after 2000. BMC Pediatr., 13: 19. DOI: 10.1186/14712431-13-19.

27. Reiner M., Niermann C., Jekauc D., Woll A. (2013) Long-term health benefits of physical activity - a systematic review of longitudinal studies. BMC Public Health, 13: 813. Available from: http://www.biomedcentral. com/1471-2458/13/813.

28. Reusch J.E.B., Bridenstine M., Regensteiner J.G. (2013) Type 2 diabetes mellitus and exercise impairment. Rev. Endocr. Metab. Disord., 14: 77-86. DOI: 10.1007/s11154012-9234-4.

29. Strasser B. (2013) Physical activity in obesity and metabolic syndrome. Ann. NY Acad. Sci., 1281: 141-159. DOI: 10.1111/j.1749-6632.2012.06785.x.

30. Sun F., Norman IJ., While A.E. (2013) Physical activity in older people: a systematic review. BMC Public Health, 13: 449. Available from: http://www.biomedcentral. com/1471-2458/13/449.

31. Timmons B.W., LeBlanc A.G., Carson V., Connor Gorber S., Dillman C., Janssen I., Kho M.E., Spence J.C., Stearns J.A., Tremblay M.S. (2012) Systematic review of physical activity and health in the early years (aged 0-4 years). Appl Physiol Nutr Metab 37: 773-792. DOI: 10.1139/h2012-070.

\section{Received 27.05.2017 \\ Accepted 28.08.2017}

\section{(C) University of Physical Education, Warsaw, Poland}

\section{Acknowledgments}

The authors would like to thank to Ana Antunes, Carolina Likhatcheva, Gonçalo Matias, Márcia Freitas, Rafael Mendes and Sara Brandão for their support in the data collection. We would also to thank to RoboCorp, IIA, Polytechnic Institute of Coimbra, Portugal. 